\title{
Correlation of cervical vertebral maturity and teeth calcification stages in children with cleft lip and palate
}

\author{
Sandy Pamadya*, Azhari**, Ria Noerianingsih Firman** \\ *Oral and Maxillofacial Radiology Department, Faculty of Dentistry, Universitas Prof. Dr. Moestopo (Beragama), Jakarta, Indonesia \\ **Oral and Maxillofacial Radiology Department, Faculty of Dentistry, Universitas Padjajaran, Bandung, West Java, Indonesia \\ *JI Bintaro Permai Raya III, Bintaro, Pesanggrahan, South Jakarta, Indonesia; e-mail: sandypamadyadrg@gmail.com
}

Submitted: $2^{\text {nd }}$ January 2018; Revised: 23 ${ }^{\text {rd }}$ May 2018; Accepted: $3^{\text {rd }}$ October 2018

\begin{abstract}
Cleft lip and palate are the most common craniofacial anomalies in Indonesia. Recent publications report that there was delayed skeletal and dental age in cleft lip and palate patients. Panoramic and lateral cephalometric radiograph to evaluate growth and development through skeletal and dental age is still rarely used. The research aimed to determine the correlation between cervical vertebral maturation and teeth calcification stages in children aged 7 to 16 years old with cleft lip and palate in Unpad Dental Hospital. The research design was analytic correlation and the sample was selected using purposive sampling cross-sectional using secondary data panoramic and lateral cephalometric radiograph. The scores of cervical maturation and teeth calcification stages were then analyzed statistically using SPSS version 16. Spearman coefficient of rank correlation test showed strong correlation between cervical vertebral maturation and teeth calcification stages on all teeth, with the highest $r_{s}$ score was secondary molar $(0.734)$ and $p$ value 0.000 The conclusion of this research is that there is a strong correlation between cervical vertebral maturation and teeth calcification stages in children aged 7 to 16 years old with cleft lip and palate.
\end{abstract}

Keywords: cervical vertebral maturation stages; cleft lip and palate; teeth calcification stages

\section{INTRODUCTION}

Growth and development indicator is one of the most important things that should be considered whenever a dentist plans a treatment. Maturity levels of a man or woman can be known from different aspects, such as chronological and biological age. Choronological age is considered as a weak tool in measuring human maturity level compared with biological age. Cervical vertebral maturity and teeth calcification stages are considered more accurate to measure human maturity indicator. ${ }^{1}$ Dental and skeletal age can be seen on panoramic and lateral cephalometric radiographs. ${ }^{2}$ Both are frequently connected with each other in several researches; one of them shows strong correlation between dental and skeletal age. ${ }^{3}$

According to 2013 Indonesia Basic Health Research, cleft lip and palate cases were estimated to be found in $0.08 \%$ of the total number of children in Indonesia. ${ }^{4}$ Several publications about cleft lip and palate patients wrote that most patients had limitation and anomalies of growth and development in craniofacial region. 5,6

Commonly, a wrist-hand radiograph was used as a biological age indicator, but in dentistry, to get more accurate biological age we use cervical vertebral maturity and teeth calcification stages from panoramic and lateral cephalometric radiographs and compare each other.1,2,3 Some research indicated no significant difference when comparing dental, skeletal and chronological age in normal patients without craniofacial anomalies. ${ }^{1}$ Teeth calcification stages can be used as a maturity indicator, as accurate as cervical vertebral maturity stages. $^{2}$ Several researches in different countries showed a late dental and skeletal maturity on those who have a cleft lip and palate condition compared to those who do not have congenital growth and developmental craniofacial anomalies. , $^{7,9}$ 
The craniofacial dimension found in patients with unilateral clef lip and palate is smaller than that in normal persons, except for the size of mandible. ${ }^{5}$ There was also skeletal age delay in boys with cleft lip and palate condition. ${ }^{9}$ Both male and female children with cleft lip and palate have been found to experience growth deficiency which varies in many ways. ${ }^{6}$ A study has reported a delay in teeth calcification in patients with cleft lip and palate. ${ }^{8}$ Therefore, the purpose of this study is to determine the correlation of cervical vertebral maturity and teeth calcification stages in children aged 7 to 16 years old with cleft lip and palate in Unpad Dental Hospital, analyzed from panoramic and lateral cephalometric radiographs.

\section{MATERIALS AND METHODS}

This research has been approved by the Ethics Committee on Health Researches of the Faculty

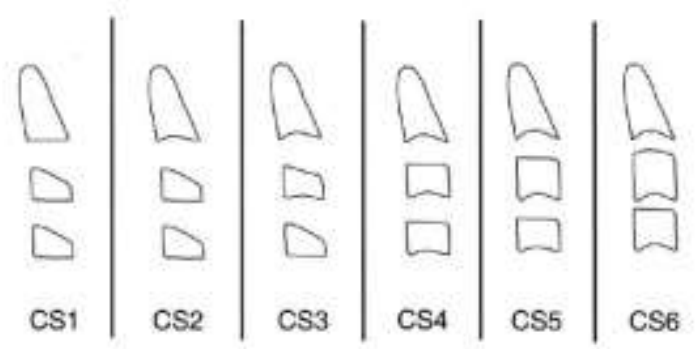

Figure 1. Baccetti's Cervical Vertebral Maturity Stages. ${ }^{10} \mathrm{CS} 1$ : The lower borders of all the three vertebrae (C2-C4) are flat. The bodies of both $\mathrm{C} 3$ and $\mathrm{C} 4$ are trapezoid in shape; CS2: concavity is present at the lower border of $\mathrm{C} 2$. The bodies of both C3 and C4 are still trapezoid in shape; CS3: Concavities at the lower borders of both $\mathrm{C} 2$ and $\mathrm{C} 3$ are present. The bodies of C3 and C4 may be either trapezoid or rectangular horizontal in shape; CS4: Concavities at the lower borders of C2, C3, and $\mathrm{C} 4$ are now present. The bodies of both $\mathrm{C} 3$ and $\mathrm{C} 4$ are rectangular horizontal in shape; CS5: The concavities at the lower borders of $\mathrm{C} 2, \mathrm{C} 3$, and $\mathrm{C} 4$ are still present. At least one of the bodies of $\mathrm{C} 3$ and C4 is square in shape; CS6: The concavities at the lower borders of $\mathrm{C} 2, \mathrm{C} 3$, and $\mathrm{C} 4$ are still evident. At least one of the bodies of $\mathrm{C} 3$ and $\mathrm{C} 4$ is rectangular vertical in shape. of Medicine Padjadjaran University number 949/UN6.C.10/PN/2017. The design of this research was cross-sectional analytic corelational study, with purposive sampling method to select samples, using secondary data in the form of panoramic and lateral cephalometric radiographs. The research was conducted in oralmaxillofacial radiology department Unpad Dental Hospital, Bandung, from April to December 2017. The samples were the panoramic and lateral cephalometric radiographs of cleft lip and palate patients aged 7 to 16 years old, from the period of January 2015 to August 2017. From the radiographs, we collected data of cervical vertebral maturity and teeth calcification stages (Figure 1 and Figure 2) which were displayed in the form of a table. Those data were then compared using Spearman Coefficient of Rank Correlation test.

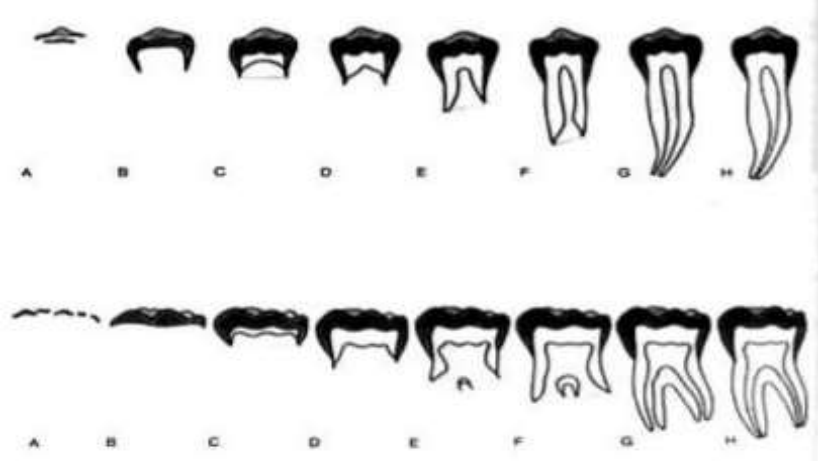

Figure 2. Demirjian's Teeth Calcification Stages. (A) Calcification of single occlusal points without fusion; (B) Fusion of mineralization points; $(C)$ Enamel formation completed at the occlusal surface, dentin formation started; (D) Crown formation complete to the CEJ, root formation commenced; (E) Root length less than crown height, bifurcation commenced calcification; (F) Root length equal or greater than crown height, roots have distinct form; $(G)$ The walls of the root canal are parallel, apical end open; $(\mathrm{H})$ The root apex is completely closed, periodontal ligaments are uniform throughout. ${ }^{3}$ 


\section{RESULTS}

The samples consisted of 49 panoramic and lateral cephalometric radiographs, but only 43 radiographs matched the inclusion criteria, divided into 21 radiographs of male patients and 22 radiographs of female patients. It was found there was a variety in the maturity of the teeth and cervical vertebrae in children with cleft lip and palate. The Spearman coefficient of rank correlation test (Table 1) showed that the second molar had the highest coefficient value $(\rho=0.734)$, and the first molar had the lowest coefficient value $(\rho=0.598)$. It was found there is strong positive correlation of cervical vertebral maturity and teeth calcification stages in children aged 7 to 16 years old with cleft lip and palate $(p=$ 0.000) (Table 1).

Table 1. Spearman coefficient of rank correlation test between cervical vertebrae maturity (CS1-CS6) and teeth calcification (A-H) stages of each tooth

\begin{tabular}{lccc}
\hline Tooth & $\begin{array}{c}\text { Number of } \\
\text { samples }\end{array}$ & $\begin{array}{c}\text { Correlation } \\
\text { coefficient }(\rho)\end{array}$ & p value \\
\hline Canine & 43 & 0.673 & 0.000 \\
Premolar 1 & 43 & 0.690 & 0.000 \\
Premolar 2 & 43 & 0.697 & 0.000 \\
Molar 1 & 43 & 0.598 & 0.000 \\
Molar 2 & 43 & 0.734 & 0.000 \\
\hline
\end{tabular}

The results of this study showed that second molar's calcification stages had the strongest significant relationship with cervical vertebral maturity than other teeth. Based on that, we predict cervical vertebrae maturity stages by seeing the calcification stages of mandibular second molars as seen in Table 2. For example, if someone's mandibular second molar's calcification stage is stage $\mathrm{F}$ with age estimation 10 to 11 years old, it is suggested that the cervical vertebral maturity stage is between stage CS3 and CS4.

\section{DISCUSSION}

In this study we used a total of 49 panoramic and lateral cephalometric radiograph samples of children aged 7 to 16 years old with cleft lip palate during a period of 2.5 years (from January 2015 to August 2017). The data distribution showed that there were several differences in the teeth calcification stages in these samples with same or slightly different chronological age. This result is in line with a study by Huykens et al, showing that there is a difference in the dental and skeletal age in patients with unilateral cleft lip and palate as well as difference in tooth calcification stages. ${ }^{6}$

Cleft lip and palate are mostly caused by genetic variants, thus there is a possibility that such condition also affects cervical vertebral maturity and teeth calcification process. In fact, the variety of the observation result is due to the ability to identify the stages or the methodology used to estimate dental and skeletal age which was based on researches whose samples were mainly from Caucasoid race, so this might be quite inaccurate when used to analyze samples from Deutero-Malay race.

The Spearman's rank correlation coefficient showed that there was a strong significant relationship between cervical vertebral maturity and

Tabel 2. Estimation of age and cervical vertebral maturity based on tooth calcification stages of mandibular second molar

\begin{tabular}{cccc}
\hline $\begin{array}{c}\text { Calcification stages of mandibular } \\
\text { second molar }\end{array}$ & $\begin{array}{c}\text { Average age estimation } \\
\text { (months) }\end{array}$ & $\begin{array}{c}\text { Cervical vertebral maturity stage } \\
\text { estimation }\end{array}$ & $\begin{array}{c}\text { Number of } \\
\text { samples }\end{array}$ \\
\hline D & $97 \pm 9$ & CS 1-CS 2 & 12 \\
E & $126 \pm 12$ & CS 2 - CS 3 & 9 \\
F & $141 \pm 12$ & CS 3 - CS 4 & 13 \\
G & $167 \pm 14$ & CS 4-CS 5 & 7 \\
H & $186 \pm 22$ & CS 5 & 2 \\
\hline
\end{tabular}

Note:

$D, F, E, G, H=$ Calcification stages of mandibular second molars

CS1-CS5 = Cervical vertebral maturity stage estimation based on calcification stage of mandibular second molars 
tooth calcification stages and second molars. The result of this study is similar to those of previous studies, revealing an association between tooth and cervical vertebral maturity in people without craniofacial anomalies. $1,2,3,11,12$

Strong significant association between cervical vertebral maturity and tooth calcification stages in children aged 7 to 16 years old with cleft lip and palate may occur because both had normal condition and craniofacial anomalies had no effects, or because both cervical vertebrae and tooth had accelerated or delayed maturity. The development of mandibular second molar starts at the age of 3 years, the crown formation finishes at the age of 7 to 8 years, and the root formation finishes at the age of 14 to 15 years. Cervical vertebral maturation process begins at the age of 7 years and ends at the age of 16 years. Both processes have an intersect timeline, so it is likely the reason why mandibular second molar's calcification stage has the strongest significant relationship with cervical vertebral maturity.

In several studies about cervical vertebral maturity, it is found that there is a delayed maturity in patients with cleft lip and palate compared with those without the condition. 5,7,8,9,13 Based on this study we strongly recommend to predict cervical vertebral maturity stages by seeing the calcification stage of second molars through panoramic radiographs.

Further studies are necessary to add more samples since this study used only 43 panoramic and lateral cephalometric radiographs, with unequally distributed data and without age and sex grouping. For example, stage $\mathrm{H}$ tooth calcification used only two samples and both had stage CS5 of cervical vertebral maturity, which cannot represent the whole condition because commonly the root formation of second molars already completes at the chronological age of 14 years old, and according to Baccetti (2005), the age of $166 \pm 13$ months (14 to 15 years old) is in stage CS6 of cervical vertebral maturity. ${ }^{10}$ It is recommended that future studies use more samples, conduct age and sex grouping, and employ new identification method for cervical vertebrae and teeth calcification stages which is already tested for Deutro-Malay race so as to make the results more accurate.

\section{CONCLUSION}

This research concludes that there is a strong relationship between cervical vertebral maturity and teeth calcification stages, especially secondary molars, based on panoramic and lateral cephalometric radiograph of children aged 7 to 16 years old with cleft lip and palate.

\section{REFERENCES}

1. Ramos, Norma AA, Lozano, Mauricio B, Ocampo, Arcelia M. Comparative analysis between dental, skeletal and chronological age. Revista Mexicana de Ortodoncia. 2013; 1(1): 33-37.

2. Ravadgar M, Mirshekar A, Moudi E, Bijani A. Association between teeth development in panoramic radiograph and skeletal maturity in lateral cephalogram. Avicenna J Dent Res. 2015; 7(2): e25051.

3. Morris JM, Park JH. Correlation of dental maturity with skeletal maturity from radiographic assessment: a review. J Clin Pediatr Dent. 2012; 36(3): 309-314.

4. Badan Penelitian dan Pengembangan Kesehatan Kementerian Kesehatan RI. Riset Kesehatan Dasar 2013. Accessible at: www.depkes.go.id/resources/download/ general/HasilRiskesdas2013.pdf.

5. Horswell, Bruce B, Levant, Bruce A. Craniofacial growth in unilateral cleft lip and palate: skeletal growth from eight to eighteen years. Cleft Palate J. 1988; 25(2): 114-121.

6. Bowers, Evelyn J. Growth in children with clefts: Serial hand-wrist X-ray evidence. Cleft Palate Craniofacial J. 2011; 48(6): 762-772.

7. Wangsrimongkol $B$, et al. Comparison of dental age development between non-cleft children and cleft lip and palate children by panoramic radiograph Scientific Cooperations International Workshops on Medical Topics; 2014 Jun 7-8; Ankara (Turkey). Scientific Cooperations Publications; 23-26. Accessible at: http://med-scoop.org/papers_2014.html. 
8. Huyskens, Rinske WF, Katsaros C, Van't Hof, Martin A, Kuijpers-Jagtman, Anne M. Dental age in children with a complete unilateral cleft lip and palate. Cleft Palate Craniofac J. 2006; 43(5): 612-615.

9. Topolski F, Boscheti de SR, Franco A, Cuoghi OA, Reichert da SAL, Fernandes A. Dental development of children and adolescents with cleft lip and palate. Braz J Oral Sci. 2014; 13(4): 319-324.

10. Baccetti T, Franchi L, McNamara Jr, James A. The Cervical Vertebral Maturation (CVM) method for the assessment of optimal treatment timing in dentofacial orthopedics. Seminars in Orthodontics. 2005; 11(3): 119-129. doi: 10.1053/j.sodo.2005.04.005.
11. Baba, Shah AF, Shahnaz N, Yousuf A, Adhnan, Kanji M. Correlation between Dental Maturity and Cervical Vertebral Maturity amongst 7 - 15 Year Old Kashmiri Children. Sch. J. Dent. Sci. 2015; 2(3A): 259-264.

12. Chongcharueyskul $P, \quad$ Wangsimongkol T, Pisek P, Pisek A, Manosudprasit M. Correlations between Cervical Vertebral Maturation (CVM) and Dental Development in Thai Cleft Patients. J Med Assoc Thai. 2015; 98: S92-S100.

13. Swennen G, Berten JL, Kramer FJ, Malevez C, De Mey A, Schwestka-Polly R, Hausamen JE. Mandibular morphology in complete unilateral cleft lip and palate. Cleft Palate Craniofac J. 2004; 41(4): 403-409. 